\title{
Vascular endothelial growth factor in systemic lupus erythematosus: relationship to disease activity, systemic organ manifestation, and nailfold capillaroscopic abnormalities
}

\author{
Anna Kuryliszyn-Moskal, Piotr Adrian Klimiuk, Stanisław Sierakowski \\ and Mariusz Ciołkiewicz
}

Department of Rheumatology and Internal Diseases, Medical University of Białystok, Białystok, Poland

Received: 2006.10.18, Accepted: 2006.12.28, Published online first: 2007.06.08

\begin{abstract}
Introduction: The aim of the study was to evaluate whether vascular endothelial growth factor (VEGF) serum level is associated with systemic organ involvement, microvascular changes as determined by nailfold capillaroscopy, and disease activity of systemic lupus erythematosus (SLE).

Materials and Methods: Serum levels of VEGF were determined by an enzyme-linked immunosorbent assay in 47 SLE patients and in 30 healthy controls. Nailfold capillaroscopy was performed in all patients and healthy subjects.

Results: Morphological changes were observed by nailfold capillaroscopy in 45 of 47 (95.7\%) SLE patients. Mild capillary changes were found in $16(34 \%)$, moderate in 21 (44.7\%), and severe in 8 (17\%) SLE patients. All patients with systemic organ involvement showed severe or moderate changes in nailfold capillaroscopy. In comparison with the control group, a higher serum concentration of VEGF in SLE patients was demonstrated $(\mathrm{p}<0.05)$. Furthermore, significant differences in VEGF serum concentration between SLE patients with systemic involvement and controls were found $(\mathrm{p}<0.01)$. Comparison between patients with active and inactive SLE according to SLEDAI score showed a significantly higher concentration of VEGF in the sera of patients with active SLE $(p<0.01)$. The SLE patients with severe and moderate changes in nailfold capillaroscopy showed significantly higher VEGF serum levels than SLE patients with mild changes $(p<0.05)$ or healthy controls $(\mathrm{p}<0.01)$. Moreover, the VEGF serum level correlated significantly with ESR $(\mathrm{r}=0.580, \mathrm{p}<0.0001)$ and CRP $(\mathrm{r}=0.512, \mathrm{p}<0.005)$.

Conclusions: Our data suggest that VEGF serum level may be a useful marker of disease activity and internal organ involvement in SLE patients. Abnormalities in nailfold capillaroscopy may reflect the extent of microvascular involvement and are associated with systemic manifestation in SLE.
\end{abstract}

Key words: systemic lupus erythematosus, vascular endothelial growth factor, nailfold capillaroscopy, systemic involvement.

Abbreviations: SLE - systemic lupus erythematosus, VEGF - vascular endothelial growth factor, SSc - systemic sclerosis, RA - rheumatoid arthritis, CTD - connective tissue disease, SLEDAI - Systemic Lupus Erythematosus Disease Activity Index, HRCT - high-resolution computed tomography, ESR - erythrocyte sedimentation rate, CRP - C-reactive protein.

Corresponding author: Anna Kuryliszyn-Moskal, Department of Rheumatology and Internal Diseases, Medical University of Białystok, M. Curie-Sklodowskiej 24a, 15-276 Białystok, Poland, tel.: +48 85 746-84-82, fax: +48 85 746-86-06, e-mail: akuryl@amb.edu.pl

\section{INTRODUCTION}

Systemic lupus erythematosus (SLE) is a progressive autoimmune disease with a wide range of clinical and immunological abnormalities. The clinical expression of SLE is the consequence of its complex immunopathology, involving the production of autoantibodies and immune complex vasculitis with endothelial cell damage [1]. The vascular endothelial injury associated with chronic systemic inflammation leads to blood vessel destruction and serious internal organ dysfunction [5, 16]. Therefore, early detection of vascular involvement plays an essential role in the diagnostic procedure of connective tissue diseases (CTDs). 
Nailfold capillary microscopy has been used as a non-invasive technique for investigating microvascular involvement in rheumatic diseases $[6,8,9,10]$. In our previous study, morphological changes in nailfold capillaroscopy in rheumatoid arthritis (RA) and CTD patients have been observed $[17,18]$. In SLE patients, a variable prevalence of capillary abnormalities has been reported [3,20]. Moreover, the nailfold capillaroscopic changes seem to be related to the disease activity score and the presence of specific autoantibodies [25].

The process of new microvessel formation, known as angiogenesis, plays an essential role in the tissue remodeling that occurs in chronic inflammatory rheumatic diseases [15, 27, 28]. Vascular endothelial growth factor (VEGF), a key modulator of angiogenesis, endothelial cell proliferation and migration, chemotaxis, and capillary hyperpermeability, is upregulated in a number of physiological and pathological conditions associated with hypoperfusion and/or hypoxia [7, 23]. Elevated levels of VEGF have been reported in the serum of patients with RA, polymyositis/dermatomyositis, and active SLE compared with healthy individuals [13]. Furthermore, it has been reported that high VEGF levels may be associated with the disease activity of RA [12, 21] and SLE [26]. In our previous studies we demonstrated significantly elevated serum levels of VEGF in RA patients with distinct variants of rheumatoid synovitis [14] and in the sera of patients with systemic sclerosis (SSc) [19] compared with healthy controls. Moreover, SSc patients with internal organ involvement showed significantly higher levels of VEGF compared with those without any evidence of systemic manifestations [19].

Based on findings suggesting an important role of endothelial activation in the pathogenesis of some extraarticular manifestations in rheumatic diseases, we evaluated whether the VEGF serum level is associated with systemic organ involvement, microvascular changes as seen in nailfold capillaroscopy, and disease activity of SLE.

\section{MATERIALS AND METHODS}

\section{Patients}

Forty-seven patients (44 women and 3 men, mean age: $41.3 \pm 13.8$ years) who fulfilled the updated 1982 American College of Rheumatology (ACR) revised criteria for SLE [29] were included in the study, giving their informed consent. The mean duration of the disease was $8.1 \pm 7.8$ years. All patients were evaluated by extensive clinical and laboratory studies. Physical examination was performed on the day of blood collection. Global disease activity was assessed using the Systemic Lupus Erythematosus Disease Activity Index (SLEDAI) [2]. The maximum score in this system is 105 points. In the present study, the number of points ranged from 3 to 22 and we considered a score
$<12$ points as inactive disease (28 patients) and a score $\geq 12$ points as active disease (19 patients).

All SLE patients were classified into two groups: those with internal organ involvement (26 cases) and 21 persons without any evidence of systemic organ manifestations in the course of SLE. The group of 26 cases with internal organ manifestations included 12 patients with renal involvement (lupus nephritis, proven histologically), 3 patients with lung fibrosis on high-resolution computed tomography (HRCT) examination, 5 patients with cardiovascular manifestations, 9 patients with central nervous system manifestations (in the form of cognitive dysfunction, severe anxiety, and altered mental function with impaired orientation), and 7 patients with severe vasculitis (ulceration, infarction, gangrene). In 12 patients, cutaneous vasculitis was observed. Table 1 shows the characteristics of the patient groups.

Table 1. Main clinical and laboratory features of SLE patients (mean $\pm \mathrm{SD})$

\begin{tabular}{|c|c|c|}
\hline Characteristics & Number of patients & Percent \\
\hline $\operatorname{Sex}(M / F)$ & $3 / 44$ & \\
\hline Age (years; mean \pm SD) & $\begin{array}{c}40.8 \pm 13.6 \\
\text { (range: } 20-71 \text { ) }\end{array}$ & \\
\hline $\begin{array}{l}\text { Disease duration } \\
\text { (years; mean } \pm \mathrm{SD} \text { ) }\end{array}$ & $\begin{array}{c}8.1 \pm 7.8 \\
\text { (range: } 0.5-29 \text { ) }\end{array}$ & \\
\hline SLEDAI (mean \pm SD) & $11.2 \pm 4.5$ & \\
\hline Active/inactive & $19 / 28$ & $40.4 / 59.6$ \\
\hline Fever & 12 & 25.5 \\
\hline Cutaneous involvement & 24 & 51.1 \\
\hline Arthritis & 25 & 53.2 \\
\hline Renal involvement & 12 & 25.5 \\
\hline Cardiac involvement & 5 & 10.6 \\
\hline Neurological involvement & 9 & 19.1 \\
\hline Anemia (hemoglobin $<12$ g/dl) & 17 & 36.2 \\
\hline $\begin{array}{l}\text { Leukopenia } \\
\text { (white blood cells }<3.5 \times 10^{9} / 1 \text { ) }\end{array}$ & 11 & 23.4 \\
\hline $\begin{array}{l}\text { Thrombocytopenia } \\
\left.\text { (platelets }<150 \times 10^{9} / 1\right)\end{array}$ & 8 & 17.0 \\
\hline $\operatorname{ESR}(\mathrm{mm} / \mathrm{h} ;>20 \mathrm{~mm} / \mathrm{h})$ & 41 & 87.2 \\
\hline $\mathrm{CRP}(>5.0 \mathrm{mg} / \mathrm{l})$ & 13 & 27.7 \\
\hline ANA positive & 38 & 80.9 \\
\hline Anticardiolipin antibody & 8 & 17.0 \\
\hline \multicolumn{3}{|l|}{ Treatment: } \\
\hline low-dose steroids & 21 & 44.6 \\
\hline high-dose steroids & 26 & 55.3 \\
\hline hydroxychloroquine & 21 & 44.6 \\
\hline immunosuppressive agents & 6 & 12.8 \\
\hline
\end{tabular}

Twenty-one patients were treated with prednisolone at a low dosage ( $\leq 10 \mathrm{mg} /$ day), 26 patients were receiving higher doses of steroids ( $>10 \mathrm{mg} /$ day $), 21$ patients hydroxychloroquine, and 6 patients immunosuppressive agents (cyclophosphamide). Higher doses of steroids and immunosuppressive drugs were not used during the two months prior to blood examination.

Control sera were obtained from 30 healthy subjects matched for sex and age. 
The study protocol was approved by the local ethics committee and the patients' written consent was obtained.

\section{Clinical and laboratory analysis}

Clinical, capillaroscopic, and laboratory data recorded at the time of serum collection included pulmonary and renal function tests, renal sonography as well as erythrocyte sedimentation rate (ESR), C-reactive protein (CRP) concentration measured by a radial immunodiffusion kit (Nanorid, The Binding Site Ltd., Birmingham, UK), hemoglobin, platelet counts, urine analysis, serum creatinine, and urinary protein excretion.

Organ system involvement was defined as: lung (bibasilar pulmonary fibrosis on HRCT), heart involvement (pericarditis or congestive heart failure on echocardiography), and kidney (renal function tests and sonography). Renal biopsy was done if patients fulfilled the ACR criteria for renal involvement, i.e. persistent proteinuria $>0.5 \mathrm{~g} / 24 \mathrm{~h}$ or cellular casts in the absence of infection [29]. In patients with central nervous system manifestations such as psychosis, organic brain syndrome, lupus headache or cerebrovascular incident, computed tomography was performed.

\section{Nailfold capillaroscopy}

Nailfold capillaroscopy was performed in all patients and healthy subjects using a stereomicroscope SZ 4045 (Olympus, Germany) by one investigator with 16 years of experience in performing nailfold capillaroscopy. A fiber-optic light source and filter provided cold illumination. Each patient was acclimatized for $20 \mathrm{~min}$ at a room temperature of $20-24^{\circ} \mathrm{C}$ prior to the examination.

The nailfolds of all fingers except the thumbs and fingers affected by recent local trauma were examined in each patient. To obtain the best visibility of the microvascular network, a drop of immersion oil was placed on the nailfold bed. Only the capillaries in the distal row of the nailfold were analyzed. The intensity of the morphological changes was evaluated on the basis of a semiquantitative method which included the parameters: loop density, capillary length variability (shorter or longer capillaries), percentage of loops with architectural derangement such as tortuous, meandering, enlarged, ramified, or bushy capillaries, irregular distribution of the capillary array, and the presence of extravasations into the perivascular tissue. The intensity of capillaroscopic changes was expressed according to a previous classification [18] and ranged from 0 to 3 , where a score of 0 indicated no changes or less than $25 \%$ morphologically changed capillaries without perivascular changes, one were mild (25-50\% morphologically changed capillaries without perivascular changes), two moderate (50-75\% morphologically changed loops with diminished loop density, increased visibility of the sub-papillary venular plexus, and without extravasations), and three were severe changes (more than $75 \%$ morphologically changed loops with the extended architectural derangement of the microvascular network, heterogeneous features of angiogenesis, extravasations into the perivascular tissue, and extensive visible venous plexus). The mean score for each subject was obtained from analysis of all the fingers.

\section{Serum specimen preparation}

Blood samples were clotted for $30 \mathrm{~min}$ and then centrifuged for $10 \mathrm{~min}$ at $1000 \times \mathrm{g}$. Serum aliquots were frozen at $-80^{\circ} \mathrm{C}$ immediately after collection.

\section{Laboratory studies}

The screening for the presence of autoantibodies to nuclear antigens (ANAs) was performed by indirect immunofluorescence microscopy on a commercial human Hep-2 cell substrate (Viro-Immun Labor Diagnostica GmbH, Germany). Serial dilutions of the sera were tested and ANA titer 11:80 was considered to be positive. Levels of IgG and IgM anticardiolipin antibodies (ACA) were measured using commercial ELISA kits (Pharmacia Diagnostics $\mathrm{AB}$ GmbH Freiburg, Germany). The serum concentrations of VEGF were assessed by an ELISA kit from R\&D Systems, Wiesbaden-Nordenstadt, Germany. Assays were carried out according to the manufacturers' instructions.

\section{Statistical analysis}

Data were analyzed by the Mann-Whitney U-test. The probability of differences in frequency distributions was determined by chi-square test or Fisher's exact test. Data were correlated by Spearman's rank order test. $\mathrm{p}$ values lower than 0.05 were considered statistically significant.

\section{RESULTS}

The characteristics of SLE patients with and without systemic organ involvement are shown in Table 2. No significant differences in age, duration of disease, SLEDAI score, ESR levels, the incidence of cutaneous involvement, ANA positivity, and the presence of ACA between the two groups of SLE patients with and without systemic involvement were seen. The score of capillaroscopic changes were significantly higher in patients with systemic manifestation of the disease $(p<0.001)$.

Morphological changes in nailfold capillaroscopy were observed in 45 of 47 (95.7\%) SLE patients. Mild capillaroscopic changes were found in $16(34 \%)$, moderate in $21(44.7 \%)$, and severe in $8(17 \%)$ SLE patients. All patients with organ systemic involvement showed severe or moderate changes in nailfold capillaroscopy, whereby 7 out of $26(26.9 \%)$ had severe changes, i.e. extended architectural derangement with heteroge- 
Table 2. Main clinical and laboratory differences in SLE patients with and without systemic organ involvement

\begin{tabular}{|c|c|c|c|c|}
\hline Characteristics & SLE together & $\begin{array}{c}\text { SLE patients } \\
\text { without systemic } \\
\text { involvement }(n=21)\end{array}$ & $\begin{array}{c}\text { SLE patients } \\
\text { with systemic } \\
\text { involvement }(n=26)\end{array}$ & $\mathrm{p}$ \\
\hline $\operatorname{Sex}(M / F)$ & $3 / 44$ & $3 / 18$ & $0 / 26$ & \\
\hline Age (years; mean \pm SD) & $40.8 \pm 13.6$ & $44.2 \pm 14.3$ & $38.0 \pm 12.5$ & NS \\
\hline Disease duration (years; mean $\pm \mathrm{SD}$ ) & $8.1 \pm 7.8$ & $6.3 \pm 6.2$ & $9.5 \pm 8.7$ & NS \\
\hline SLEDAI $($ mean \pm SD) & $11.2 \pm 4.5$ & $9.8 \pm 4.0$ & $12.3 \pm 4.7$ & NS \\
\hline $\mathrm{ESR}(\mathrm{mm} / \mathrm{h} ;$ mean $\pm \mathrm{SD})$ & $34.2 \pm 24.9$ & $33.8 \pm 26.3$ & $34.6 \pm 24.3$ & NS \\
\hline Nailfold capillaroscopy (score; mean \pm SD) & $1.8 \pm 0.9$ & $1.1 \pm 0.7$ & $2.3 \pm 0.5$ & $<0.001$ \\
\hline Cutaneous involvement (n/\%) & $24 / 51.1$ & $8 / 38.1$ & $16 / 61.5$ & NS \\
\hline Raynaud's phenomenon (n/\%) & $4 / 8.5$ & $2 / 9.5$ & $2 / 7.7$ & NS \\
\hline $\mathrm{CRP}(>5.0 \mathrm{mg} / \mathrm{l} ; \mathrm{n} / \%)$ & $13 / 27.7$ & $7 / 33.3$ & $6 / 23.1$ & NS \\
\hline ANA positive (n/\%) & $38 / 80.9$ & $15 / 71.4$ & $23 / 88.5$ & NS \\
\hline Anticardiolipin antibody (n/\%) & $8 / 17.0$ & $3 / 14.3$ & $5 / 19.2$ & NS \\
\hline \multicolumn{5}{|l|}{ Treatment: } \\
\hline low-dose steroids (n/\%) & $21 / 44.7$ & $11 / 52.4$ & $10 / 38.5$ & NS \\
\hline high-dose steroids (n/\%) & $26 / 55.3$ & $10 / 47.6$ & $16 / 61.5$ & NS \\
\hline hydroxychloroquine $(\mathrm{n} / \%)$ & $21 / 44.7$ & $11 / 52.4$ & $10 / 38.5$ & NS \\
\hline immunosuppressive agents $(\mathrm{n} / \%)$ & $6 / 12.8$ & $2 / 9.5$ & $4 / 15.4$ & NS \\
\hline
\end{tabular}

NS - not significant.

neous features of angiogenesis and extravasations into perivascular tissue, and 19 out of $26(73.1 \%)$ had moderate capillary abnormalities without signs of angiogenesis and microhemorrhages. In the group without organ systemic manifestation, only one patient $(4.8 \%)$ showed severe vascular changes, two patients $(9.5 \%)$ moderate, $16(76.2 \%)$ mild capillaroscopic abnormalities, and two patients $(9.5 \%)$ had no pathological changes in nailfold capillaroscopy.

The capillaroscopic feature in the control group showed hairpin capillaries in a parallel arrangement. Isolated tortuous capillary loops and meandering, elongated capillaries were found in 5 persons $(16.6 \%)$ of the healthy controls.

Serum levels of VEGF were determined in 47 SLE patients, including 26 patients with systemic involvement, 21 cases without internal organ manifestations, and in 30 healthy subjects (Fig. 1). The SLE patients had significantly elevated serum concentrations of VEGF compared with the age-matched healthy controls $(p<0.05)$. Although the mean serum level of VEGF was higher in SLE patients with systemic involvement than in cases without organ manifestation and in the control group, a significant difference only between SLE patients with systemic involvement and controls could be shown $(\mathrm{p}<0.01)$.

Comparison between the SLE groups with active and inactive disease according to SLEDAI score showed a significantly higher concentration of VEGF in the sera of patients with active SLE $(p<0.01)$. Also, the mean serum level of VEGF was significantly higher in patients with active SLE than in the control group $(\mathrm{p}<0.001)$. However, VEGF concentrations did not differ significantly between the patients with inactive SLE and healthy controls (Fig. 2). Moreover, VEGF serum level correlated significantly with ESR $(r=0.580, \mathrm{p}<0.0001)$ and CRP $(\mathrm{r}=0.512, \mathrm{p}<0.005$; data not shown).

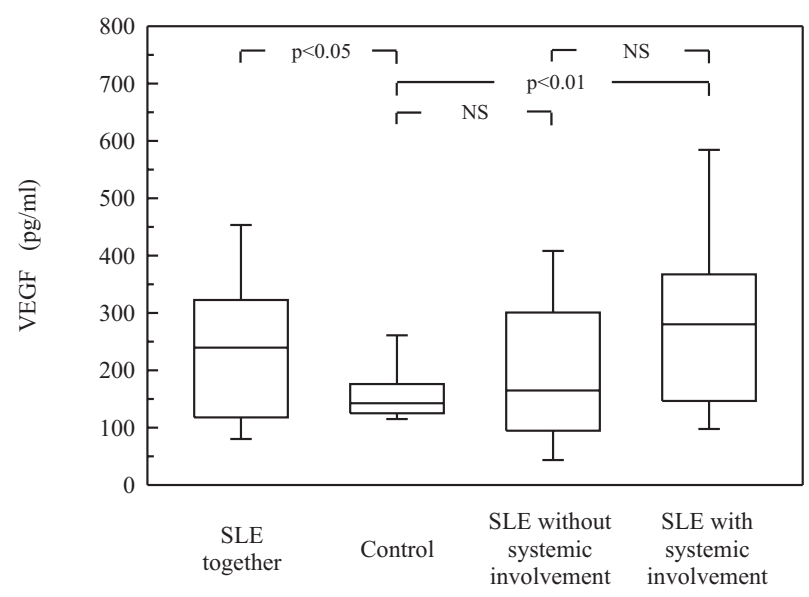

Fig. 1. Serum concentrations of VEGF in SLE patients with and without internal organ involvement. Box plots represent median (line), 25th and 75 th percentiles (box), and whiskers indicating the 10th and 90th percentiles. NS - not significant.

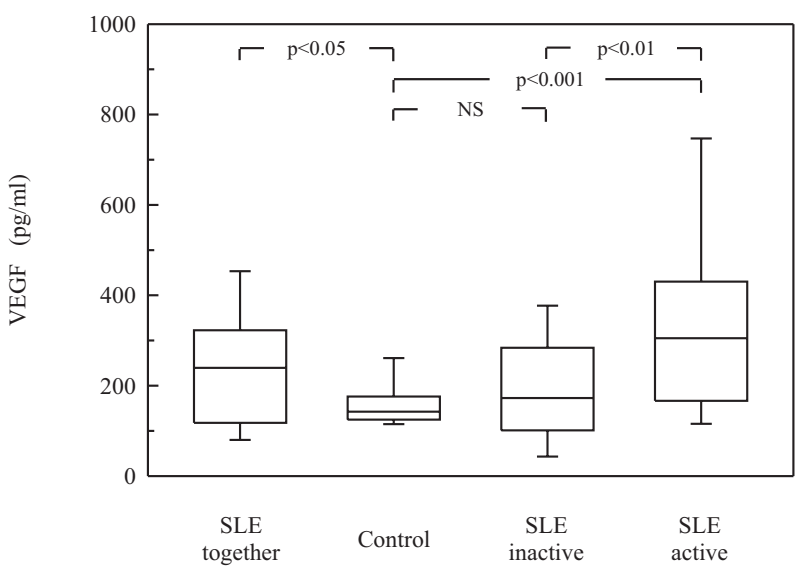

Fig. 2. Serum concentration of VEGF in patients with active and inactive SLE. Data are presented as described in Fig. 1. 


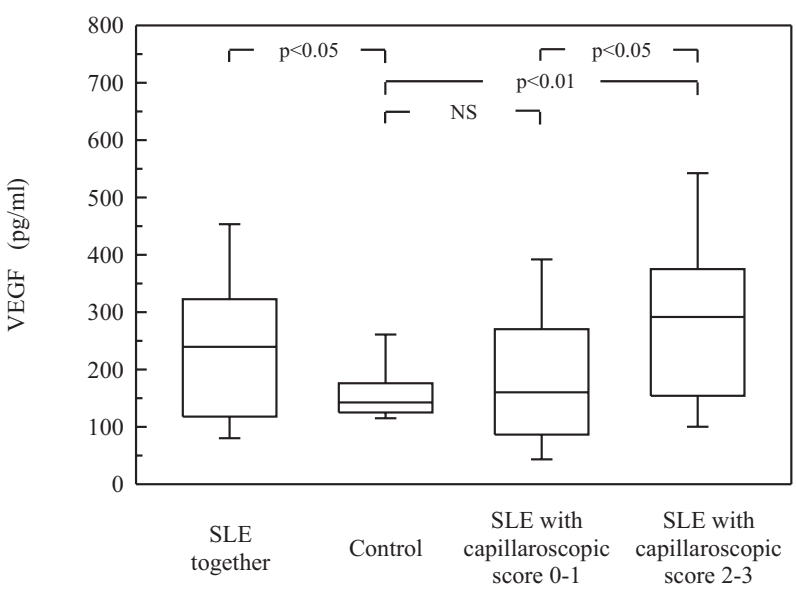

Fig. 3. Serum concentration of VEGF in patients according to the score of capillaroscopic changes (described in Materials and Methods). Data are shown as presented in Fig. 1.

SLE patients with severe and moderate changes in nailfold capillaroscopy (score $>1$ ) showed significantly higher VEGF serum levels than SLE patients with mild changes $(\mathrm{p}<0.05)$ and healthy controls $(\mathrm{p}<0.01 ;$ Fig 3$)$. Typical abnormalities representative of patients with capillaroscopic scores $0-1$ and scores $2-3$ are shown in Fig. 4A and B, respectively.

A

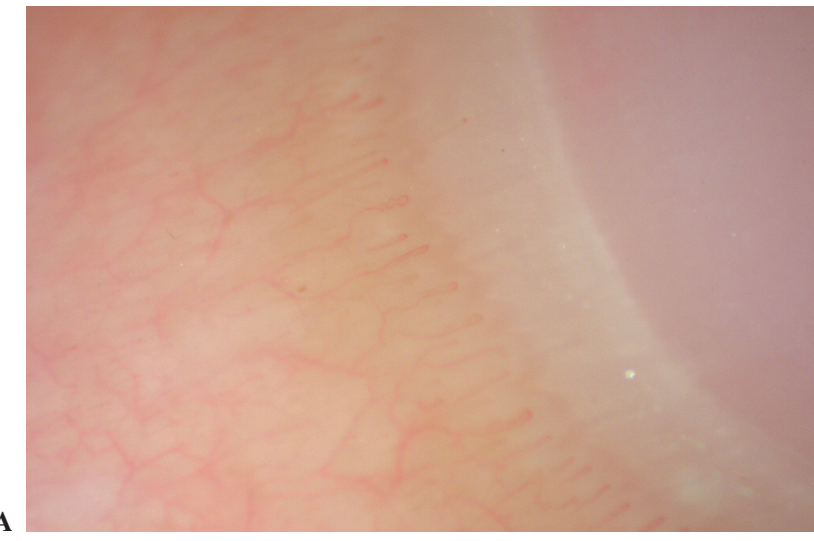

B

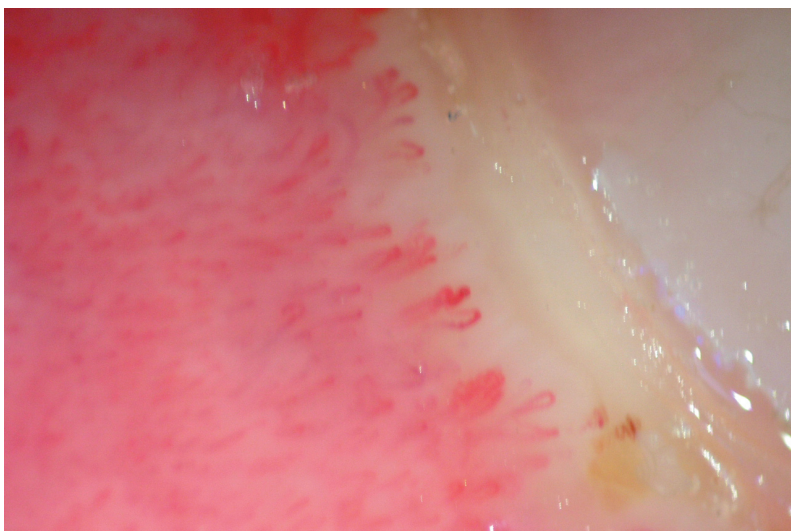

Fig. 4. Typical abnormalities representative of patients with capillaroscopic scores $0-1$ and scores $2-3$ are shown in Fig. 4A and $\mathbf{B}$, respectively. Details described in the text.

\section{DISCUSSION}

Recently, many studies have concentrated on the role of angiogenesis and microvascular endothelial injury in the pathogenesis of systemic organ involvement in rheumatic diseases, such as SLE [4]. One of the key players in the process of new vessel formation is VEGF [7, 23]. Several studies have reported elevated levels of VEGF in the plasma [22] and serum [26] of SLE patients. Moreover, a relationship between VEGF serum levels and SLE activity score was observed [26]. Other investigators reported that VEGF is increased in plasma from patients with lupus nephritis and a moderate degree of renal failure [22]. Since in our previous study a relationship between capillaroscopic abnormalities and extra-articular manifestations of RA and CTD patients was observed [18], we investigated whether the VEGF serum level is associated with systemic organ involvement, microvascular capillaroscopic changes, and disease activity in SLE patients.

In our previous study we demonstrated that systemic lesions in the course of RA and CTD are accompanied by microvascular injury observable under capillary microscopy [18]. Growing evidence points to the diagnostic value of nailfold capillaroscopy in rheumatic diseases $[6,8,9,10]$. However, little data exist on the relationship between immunological alterations, internal organ involvement, and capillaroscopic abnormalities.

In the present study, all SLE patients with internal organ manifestations showed severe $(26.9 \%)$ or moderate $(73.1 \%)$ pathological changes under nailfold capillaroscopy. Mild changes in capillaroscopy in patients with systemic involvement were not observed. In the group without systemic manifestations, only one patient $(4.8 \%)$ showed severe and two patients $(9.5 \%)$ moderate vascular abnormalities. In four patients with Raynaud's phenomenon, the so-called capillaroscopic SD-pattern (scleroderma disease pattern) was observed.

Although capillaroscopic changes are not specific to SLE, we demonstrated more severe morphological abnormalities, such as extended architectural derangement with heterogeneous features of angiogenesis and microhemorrhages in patients with higher disease activity. Only one patient with inactive SLE had severe vascular changes. This may confirm the findings of other authors [25] that microvascular changes may be related to a more severe disease state. Moreover, it has been demonstrated that severe capillaroscopic abnormalities correlated with the presence of the main autoantibodies $[24,25]$ and pulmonary function impairment [11]. In our study, three patients with pulmonary involvement showed severe vascular changes.

In the present study, the VEGF serum concentration was significantly higher in all SLE patients compared with healthy controls. Moreover, VEGF reached the highest serum levels in patients with organ involvement, although no significant differences between the 
SLE groups with and without systemic manifestations were found. Other investigators reported that patients with renal failure had significantly elevated plasma levels and overexpression of VEGF in renal tissue compared with SLE patients with normal renal function [22]. It is postulated that this factor might be involved in glomerular endothelial repair [22]. In our study 12 out of $26(46.2 \%)$ SLE cases with internal organ manifestation had renal involvement. No significant differences between SLE patients without systemic involvement and healthy controls may confirm that VEGF may be a useful marker of systemic involvement in SLE patients.

It has been postulated that inflammation may have an influence on endothelial function in rheumatic diseases [30]. The results of this study confirm that in patients with active SLE the serum concentration of VEGF is significantly higher than in healthy controls or patients with inactive disease [26]. It is postulated that the imbalance between VEGF and its soluble receptors may be important in the pathogenesis of SLE [26]. Moreover, we demonstrated correlation of VEGF with such clinical and laboratory markers of disease activity as ESR and CRP. In our previous study, serum concentration of VEGF was found to correlate with ESR and CRP in RA patients [14].

In the present study we demonstrated significantly higher serum levels of VEGF in SLE patients with severe and moderate abnormalities in capillaroscopy compared with patients with mild changes. Among the 29 patients with severe or moderate changes in nailfold capillaroscopy, 15 cases $(51.7 \%)$ were active according to the SLEDAI score and in the group with mild vascular changes, 4 patients out of $18(22.2 \%)$ had active disease. Therefore, further studies are needed to confirm whether the serum level of VEGF reflects the extent of microvascular damage in SLE patients.

Although the titer of anti-dsDNA antibodies were higher in the group with systemic involvement compared with those without this complication, no correlation between the autoantibodies and VEGF serum levels was found (data not shown). In addition, serum concentrations of VEGF did not differ significantly between the patients with and without immunosuppressive treatment (data not shown).

Our findings point to an important role of VEGF in the pathogenesis of systemic organ involvement in SLE patients. Abnormalities in nailfold capillaroscopy may reflect the extent of microvascular involvement in SLE. Nailfold capillaroscopy can be useful in the diagnostic procedure of the disease and lead to more effective strategies in the treatment of systemic organ dysfunction in SLE.

In conclusion, the serum level of VEGF may be a useful marker of disease activity and internal organ involvement in SLE patients. Nailfold capillaroscopy abnormalities may reflect the extent of microvascular involvement and are associated with systemic organ manifestations in SLE.

\section{REFERENCES}

1. Belmont H. M., Abramson S. B. and Lie J. T. (1996): Pathology and pathogenesis of vascular injury in systemic lupus erythematosus. Interaction of inflammatory cells and activated endothelium. Arthritis Rheum., 39, 9-22.

2. Bombardier C., Gladman D. D., Urowitz M. B., Caron D. and Chang C. H. and Commitee on Prognosis Studies in SLE (1992): Derivation of the SLEDAI. A disease activity index for lupus patients. Arthritis Rheum., 35, 630-640.

3. Bongard O., Bounameaux H., Miescher P. A. and De Moerloose P. (1995): Association of anticardiolipin antibodies and abnormal nailfold capillaroscopy in patients with systemic lupus erythematosus. Lupus, 4, 142-144.

4. Clancy R., Marder G., Martin V., Belmont H. M., Abramson S. B. and Buyon J. (2001): Circulating activated endothelial cells in systemic lupus erythematosus. Further evidence for diffuse vasculopathy. Arthritis Rheum., 44, 1203-1208.

5. Cronstein B. N., Reiss A. and Malhotra S. (1999): The vascular endothelium. In Kammer G. M. and Tsokos G. C. (eds.): Lupus: Molecular and cellular pathogenesis. Humana Press, Totowa, 13-20.

6. Cutolo M., Sulli A., Pizzorni C. and Accardo S. (2000): Nailfold videocapillaroscopy assessment of microvascular damage in systemic sclerosis. J. Rheumatol., 27, 155-160.

7. Ferrara N. (1999): Molecular and biological properties of vascular endothelial growth factor. J. Mol. Med., 77, 527-543.

8. Furtado R. N., Pucinelli M. C., Cristo V. V., Andrade L. E. and Sato E. I. (2002): Scleroderma-like nailfold capillaroscopic abnormalities are associated with anti-U1-RNP antibodies and Raynaud's phenomenon in SLE patients. Lupus, 11, 35-41.

9. Grassi W., Del Medico P., Izzo F. and Cervini C. (2001): Microvascular involvement in systemic sclerosis: capillaroscopic findings. Semin. Arthritis Rheum., 30, 397-402.

10. Grassi W. and Del Medico P. (2004): Atlante di Capillaroscopia. Edra, Milano.

11. Groen H., ter Borg E. J., Postma D. S., Wouda A. A., van der Mark T. W. and Kallenberg C. G. (1992): Pulmonary function in systemic lupus erythematosus is related to distinct clinical, serologic, and nailfold capillary patterns. Am. J. Med., 93, 619-627.

12. Harada M., Mitsuyama K., Yoshida H., Sakisaka S., Taniguchi E., Kawaguchi T., Ariyoshi M., Saiki T., Sakamoto M., Nagata K., Sata M., Matsuo K. and Tanikawa K. (1998): Vascular endothelial growth factor in patients with rheumatoid arthritis. Scand. J. Rheumatol., 27, 377-380.

13. Kikuchi K., Kubo M., Kadono T., Yazawa N., Ihn H. and Tamaki K. (1998): Serum concentrations of vascular endothelial growth factor in collagen diseases. Br. J. Dermatol., 139, 1049-1051

14. Klimiuk P. A., Sierakowski S., Latosiewicz R., Cylwik J. P., Cylwik B., Skowronski J. and Chwiecko J. (2002): Soluble adhesion molecules (ICAM-1, VCAM-1, and E-selectin) and vascular endothelial growth factor (VEGF) in patients with distinct variants of rheumatoid synovitis. Ann. Rheum. Dis., 61, 804-809.

15. Koch A. E. (2003): Angiogenesis as a target in rheumatoid arthritis. Ann. Rheum. Dis., 62 (suppl. II), ii60-ii67.

16. Krishnaswamy G., Kelley J., Yerra L., Smith J. K. and Chi D. S. (1999): Human endothelium as a source of multifunc- 
tional cytokines: molecular regulation and possible role in human disease. J. Interferon Cytokine Res., 19, 91-104.

17. Kuryliszyn-Moskal A. (1998): Cytokines and soluble CD4 and CD8 molecules in rheumatoid arthritis: relationship to systemic vasculitis and microvascular capillaroscopic abnormalities. Clin. Rheumatol., 17, 489-495.

18. Kuryliszyn-Moskal A., Klimiuk P. A. and Sierakowski S. (2001): Serum autoantibodies profile and increased levels of circulating intercellular adhesion molecule-1: a reflection of the immunologically mediated systemic vasculopathy in rheumatic diseases? Arch. Immunol. Ther. Exp., 49, 423-430.

19. Kuryliszyn-Moskal A., Klimiuk P. A. and Sierakowski S. (2005): Soluble adhesion molecules (sVCAM-1, sE-selectin), vascular endothelial growth factor (VEGF) and endothelin1 in patients with systemic sclerosis: relationship to organ systemic involvement. Clin. Rheumatol., 24, 111-116.

20. Lee P., Leung F. Y., Alderdice C. and Armstrong S. K. (1983): Nailfold capillary microscopy in the connective tissue diseases: a semiquantitative assessment. J. Rheumatol., 10, 930-938.

21. Lee S. S., Joo Y. S., Kim W. U., Min D. J., Min J. K., Park S. H., Cho C. S. and Kim H. Y. (2001): Vascular endothelial growth factor levels in the serum and synovial fluid of patients with rheumatoid arthritis. Clin. Exp. Rheumatol., 19, 321-324.

22. Navarro C., Candia-Zúniga L., Silveira L. H., Ruiz V., Gaxiola M., Avila M. C. and Amigo M. C. (2002): Vascular endothelial growth factor plasma levels in patients with systemic lupus erythematosus and primary antiphospholipid syndrome. Lupus, 11, 21-24.
23. Paleolog E. M. (1996): Angiogenesis: a critical process in the pathogenesis of RA - a role for VEGF? Br. J. Rheumatol., 35, 917-919.

24. Pisetsky D. S. (1992): Anti-DNA antibodies in systemic lupus erythematosus. Rheum. Dis. North Am., 18, 437-454.

25. Riccieri V., Spadaro A., Ceccarelli F., Scrivo R., Germano V. and Valesini G. (2005): Nailfold capillaroscopy changes in systemic lupus erythematosus: correlations with disease activity and autoantibody profile. Lupus, 14, 521-525.

26. Robak E., Sysa-Jędrzejewska A. and Robak T. (2003): Vascular endothelial growth factor and its soluble receptors VEGFR-1 and VEGFR-2 in the serum of patients with systemic lupus erythematosus. Mediators Inflamm., 12, 293-298.

27. Sundy J. S. and Haynes B. F. (1995): Pathogenic mechanisms of vessel damage in vasculitis syndromes. Rheum. Dis. Clin. North Am., 21, 861-881.

28. Szekanecz Z., Szegedi G. and Koch A. E. (1998): Angiogenesis in rheumatoid arthritis: pathogenic and clinical significance. J. Investig. Med., 46, 27-41.

29. Tan E. M., Cohen A. S., Fries J. F., Masi A. T., McShane D. J., Rothfield N. F., Schaller J. G., Talal N. and Winchester R. J. (1982): The 1982 revised criteria for the classification of systemic lupus erythematosus. Arthritis Rheum., 25, 1271-1277.

30. Vaudo G., Marchesi S., Gerli R., Allegrucci R., Giordano A., Siepi D., Pirro M., Shoenfeld Y., Schillaci G. and Mannarino E. (2004): Endothelial dysfunction in young patients with rheumatoid arthritis and low disease activity. Ann. Rheum. Dis., 63, 31-35. 
